\title{
José Olympio: um editor de risco
}

Fernando Paixão

$\mathrm{E}$ MPREGADO como desempacotador de livros na Casa Garraux, em 1918, José Olympio levou cerca de uma década e meia para se tornar o editor mais influente do país. Esse fato, por si só, seria suficiente para comprovar o excepcional talento do rapaz nascido em Batatais, em 1902, que teve uma vertiginosa carreira de ascensão no meio editorial, mesmo tendo freqüentado os bancos escolares por poucos anos. Vale a pena, pois, levantar algumas considerações sobre a sua trajetória, estimuladas pelo lançamento recente de livro sobre tão notável figura: José Olympio - O editor e sua Casa, organizado e escrito pelo também editor José Mario Pereira.

JO, como passou a ser chamado, era homem intuitivo e inteligente, de boa conversa, sempre disponível para ouvir os amigos e colaboradores. Para escolher os títulos que publicava, declarou certa vez que se pautava pelo instinto. Mas também dava muitos palpites na área comercial e de propaganda. Gostava de correr riscos. Em parte, o seu sucesso pode ser explicado justamente por essa característica, aliada a uma grande capacidade de trabalho e de relacionamento pessoal. No final da vida, mesmo enfrentando dificuldades, ainda se dispôs a adquirir a Editora Sabiá, criada e dirigida por Fernando Sabino e Rubem Braga, e chegou a afirmar: "editar é uma questão de jogo".

A história de sua editora confirma essa máxima. Tudo começou no início dos anos 1930, quando despertou o movimento de renovação econômica e cultu- ral promovido pela ascensão de Getúlio Vargas ao poder. Os ventos novos da República se voltaram para uma retomada do governo federal, configurado na Constituição de 1934, e se aproveitaram de um acelerado desenvolvimento da economia que, segundo Laurence Hallewell (1985, p.337), chegou a crescer $50 \%$ em apenas sete anos.

Decidido a começar o próprio negócio, ele foi ajudado por alguns amigos, antes de abrir no Rio de Janeiro, em 1931, a sua primeira livraria, localizada na Rua da Quitanda. Três anos depois, quando iniciou de fato a atividade de editor, o estabelecimento passou a funcionar em endereço nobre, quase em frente à famosa Livraria Garnier, que fechou em seguida. Ousado e dotado da energia típica dos trinta anos, José Olympio sabia muito bem aonde queria chegar. E foi capaz de lances certeiros para alcançar seus objetivos.

O sucesso inicial veio com a obra de Humberto de Campos, logo seguida do êxito alcançado pelos "romancistas do Nordeste", com destaque para José Lins do Rego, Graciliano Ramos e Raquel de Queiróz. Em paralelo à ficção, o ano de 1936 marca o lançamento da coleção "Documentos Brasileiros", coordenada por Gilberto Freyre e que se tornou uma referência para a intelectualidade nacional. Reinvestindo os lucros, a editora obteve, durante a primeira década, a marca de quase 600 títulos produzidos, com mais de 2,2 milhões de exemplares vendidos, e a maioria expressiva do catálogo era formada por autores brasileiros. 


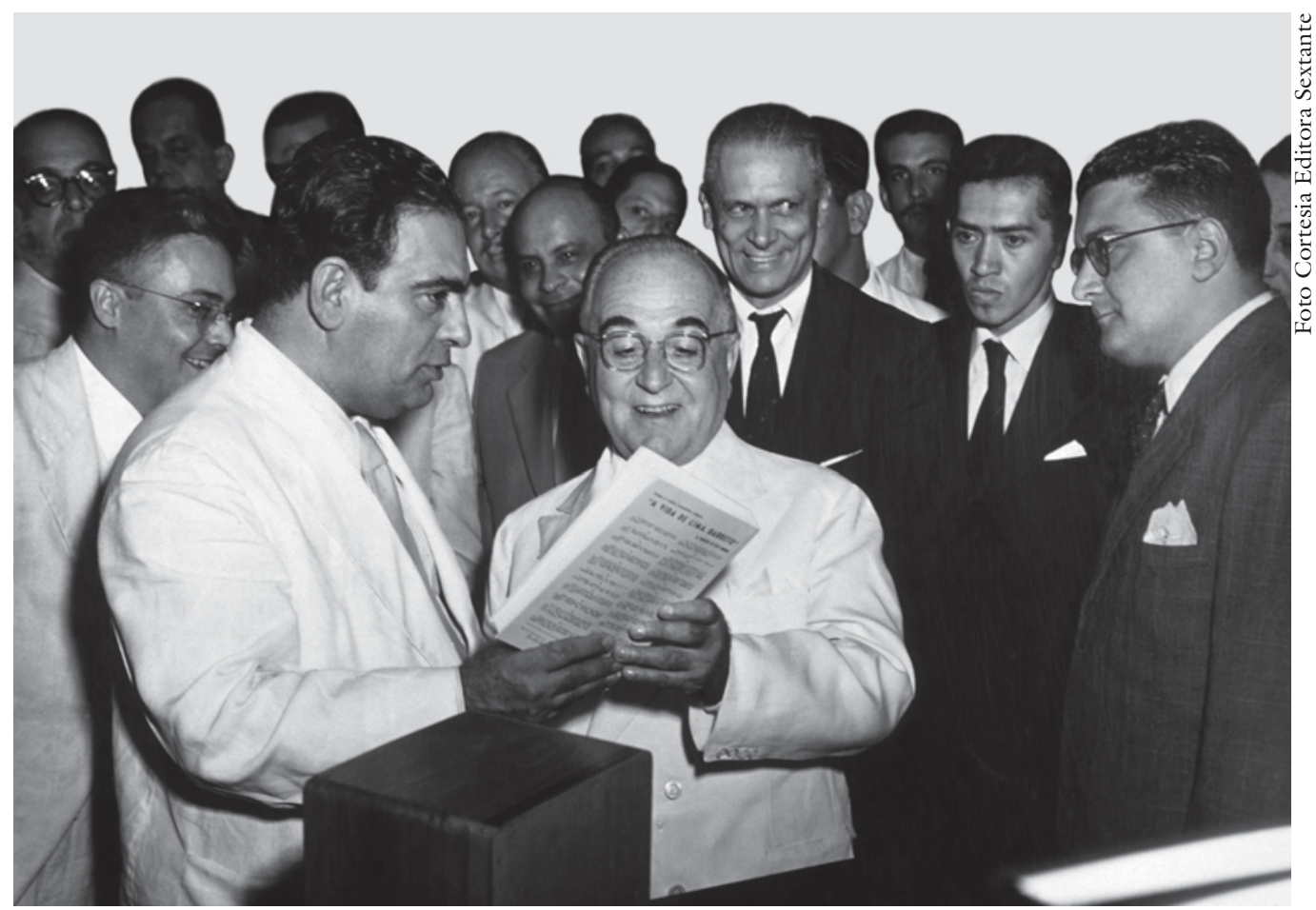

José Olympio (1902-1990) entrega a Getúlio Vargas (1882-1954) livro publicado pela Casa.

A importância de José Olympio foi de tal ordem, que Antonio Candido (1989, p.193) referiu-se a ele como um "herói cultural" da época. Ao considerá-lo com tal elogio, o crítico está na verdade reconhecendo-o como o melhor exemplo entre nós de como é possível promover e aprimorar o "sistema literário", desde que as condições sociais favoreçam a emancipação. Como se sabe, o conceito delineado por Candido contempla a formação de um "sistema de obras ligadas por denominadores comuns", a saber: os autores, os leitores e um mecanismo transmissor, representado nos estilos literários.

Associado a esse tripé, não será exagero acrescentar a figura do editor como elemento decisivo para que os escritores tenham os seus manuscritos publicados e disponibilizados para o público potencial. Pouco adianta haver uma produção literária farta e diversificada se não estiver acompanhada de divulgação abrangente, fazendo que os livros alcancem corações e mentes. Para que o sistema literário funcione de modo pleno, é estimulante a intensa circulação de idéias e textos.

Conforme a receptividade de vendas, mais ou menos altas, e de crítica, com elogios ou não, cada livro passa por uma espécie de provação. Obviamente, fatores dessa ordem não representam um julgamento final quanto à qualidade da obra, cuja avaliação envolveria outras competências. Mas servem de sinal indicativo e revelam um retrato da preferência dos leitores. Ao editor cabe justamente o papel de se tornar intérprete desse gosto geral, diante do qual ele intervém, por conta de suas escolhas de publicação. Sempre contanto com a sorte, claro.

Visto sob essa óptica, José Olympio esteve no centro do sistema literário do seu tempo. Além de publicar a produção ficcional dos autores principais da edito- 
ra, ele também solicitava traduções e encomendava textos, mantendo uma rede de colaboradores de alta qualidade e servindo de modelo para as outras empresas. Era também agressivo na promoção dos livros, ocupando-se das contracapas das publicações, mas também com bons investimentos em anúncios de revistas e jornais.

A hegemonia da Casa, como era carinhosamente conhecida a editora, estendeu-se até o começo dos anos 1960, em parte impulsionada pela intimidade que José Olympio tinha com Getúlio Vargas e outras figuras do poder. Mesmo durante o período militar, cultivou proximidade com as autoridades de Brasília, e alguns de seus concorrentes costumavam criticálo por isso. A partir de 1964, a editora foi aos poucos perdendo o fôlego e deixou de ser a principal protagonista na veiculação das nossas letras, papel que veio a compartilhar com a Civilização Brasileira, sob a coordenação de Ênio Silveira.

Ostentando reação diante da situação adversa, JO não se intimidou e, ao contrário, apostou em lances de maior risco. Decidiu investir no ramo dos livros didáticos, à custa de altos investimentos, e encantou-se com a possibilidade de ter a Editora Sabiá incorporada ao seu catálogo. Mas, dessa vez, o jogo virou e ele teve de amargar prejuízos significativos. Sua capacidade de administrador certamente não se igualava à intuição editorial, e o resultado alcançado com essas duas operações não foi dos melhores. Em 1974, a editora foi incorporada pelo BNDES e, posteriormente, vendida e descaracterizada. Atualmente seu nome é usado por um dos selos editoriais associados ao Grupo Record.

O livro ora publicado tem aspecto luxuoso, em capa dura e com belo projeto gráfico de Vitor Burton. Mario Pereira teve acesso aos arquivos da editora e, por conta disso, pôde transcrever alguns trechos de correspondências e bilhetes trocados com alguns autores. A obra também é virtuosa no que se refere aos registros fotográficos. Ao lado de fotos bem conhecidas, traz algumas imagens inéditas que transmitem o clima de amizade e cortesia que cercava José Olympio.

Sobressaem ainda inúmeras capas de livros, atestando a qualidade gráfica das publicações, envolvendo artistas do nível de Santa Rosa, Carybé, Cícero Dias e tantos outros. No entanto, os textos sobre os autores publicados pela Casa, fartamente ilustrados e ocupando a maior parte do livro, são sumários em demasia e sem novidades, ainda que compensados por legendas detalhadas, comentando as ilustrações. Como resultado final, temos um bom livro de homenagem.

Infelizmente, porém, ainda não dispomos de um livro à altura de tão rico personagem. O melhor deles continua sendo Rua do Ouvidor, 110 (José Olympio, 2006), escrito por sua neta, Lucila Soares, que apresenta uma visão amorosa do avô, entremeada de informações curiosas. ${ }^{1}$ Mas é insuficiente para entender o fenômeno da editora e do ambiente intelectual que compartilhava. A falta de dados confiáveis sobre o mercado de livros e a dificuldade de acesso às fontes primárias de pesquisa inibem um maior vôo no sentido de interpretar o contexto da época e os fatores que permitiram tão acelerada ascensão.

José Olympio deixou-nos a mostra de que não existe boa literatura sem o estímulo de condições objetivas e subjetivas para que os escritores possam desenvolver a criação. Por isso mesmo, pode ser 


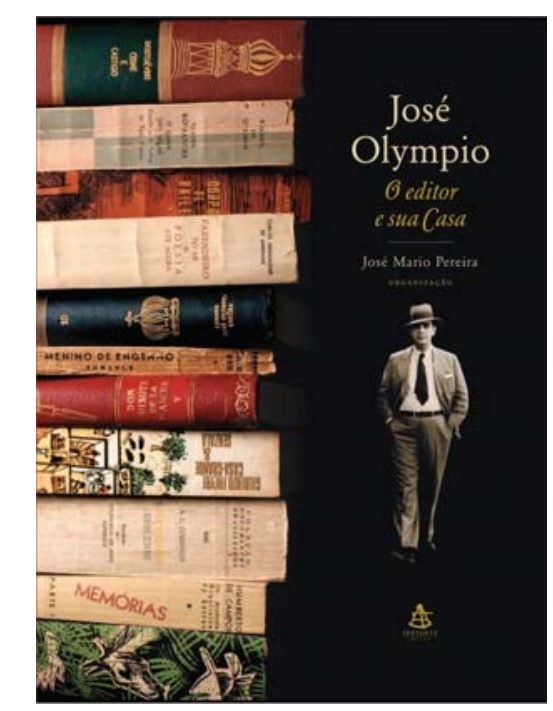

PEREIRA, José Mario (Org.) José Olympio O editor e sua Casa. Rio de Janeiro: Sextante, 2008. 424p.

considerado o nosso "Gallimard", pois, tal como o editor francês, foi capaz de cercar-se de autores talentosos e de uma equipe de ótimos profissionais. Ganhou com isso o campo literário brasileiro, que passou a ter uma referência de qualidade, com influências diretas sobre o mercado editorial que se seguiu ao apogeu da editora. Quanto melhor pudermos compreender esse exemplo do passado, melhor saberemos como atuar no presente.

\section{Nota}

1 A respeito dessa publicação, ver a resenha "Um editor das Arábias", de José Mindlin, publicado em Estudos Avançados, v.21, n.60, p.323-24. Disponível em: <http://www.scielo.br/ scielo.php?script-sci_arttext\&pid-S01030142007000200027\&lng-en\&nrm-iso> (N.E.).
Referências bibliográficas

CANDIDO, A. A revolução de 1930 e a cultura. In: _. A educação pela noite \& outros ensaios. São Paulo: Ática, 1989.

HALLEWELL, L. O livro no Brasil. São Paulo: T. A. Queiros; Editora da Universidade de São Paulo, 1985.
Fernando Paixão é editor e poeta. Publicou Poeira (Editora 34, 2001), entre outros livros, e trabalha na área editorial há mais de três décadas.

@ - fernando.paixao@uol.com.br 